\title{
Synthesis and characterization of NiS Nanoparticles@Carbon Nanofiber Composite as Electrocatalyst for Methanol Oxidation
}

\author{
Ibrahim M. Maafa \\ Chemical Engineering Department, College of Engineering, Jazan University, Jazan 45142, Saudi \\ Arabia. \\ E-mail: imoaafa@jazanu.edu.sa
}

doi: $10.20964 / 2021.04 .32$

Received: 4 December 2020 / Accepted: 21 January 2021 / Published: 28 February 2021

This study aimed at the successful synthesis of NiS nanoparticle-decorated carbon nanofibers (NiS NPs/CNFs) by the electrospinning technique and their use as an electrocatalyst for methanol oxidation. NFs were prepared from calcination of electrospun nanofiber mats composed of polyvinyl pyrrolidone, nickel acetate tetrahydrate, and ammonium sulfide at $800{ }^{\circ} \mathrm{C}$ in inert atmosphere for $5 \mathrm{~h}$. Standard characterization techniques (SEM, XRD, TEM, and TEM-EDX) showed the formation of nickel sulphide and carbon. The NiS NPs/CNFs prepared showed a good electrocatalytic activity toward methanol oxidation in alkaline media. The current density obtained was $20 \mathrm{mAcm}^{-2}$ at $4 \mathrm{M}$ methanol in $1 \mathrm{M} \mathrm{KOH}$ solution. The NiS NPs/CNFs showed a good stability for $3000 \mathrm{~s}$ used in chronoamperometry test.

Keywords: Nickel sulphide; Carbon Nanofibers; Electrospinning; Electrooxidation; Methanol

\section{$\underline{\text { FULL TEXT }}$}

(C) 2021 The Authors. Published by ESG (www.electrochemsci.org ). This article is an open access article distributed under the terms and conditions of the Creative Commons Attribution license (http://creativecommons.org/licenses/by/4.0/). 